\title{
Physician OWNed Hospitals: CongRess Should CHANGE THE ACA's COURSE OF TREATMENT
}

\author{
Melissa C. Schade van Westrum*
}

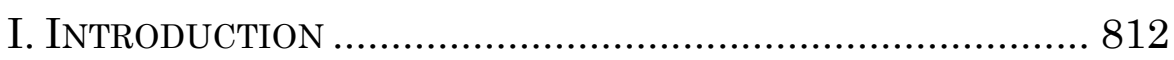

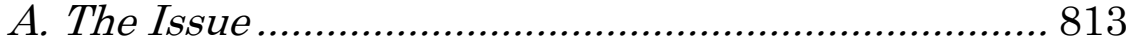

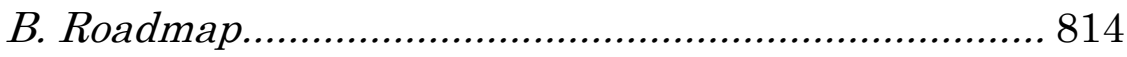

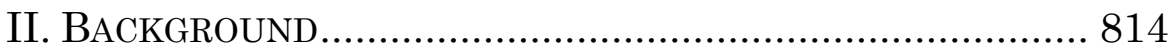

A. Federal Anti-Kickback Statute .............................. 816

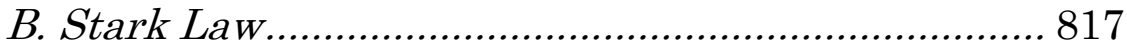

C. Medicare Modernization Act ................................. 818

III. IMPLEMENTATION OF THE ACA …............................... 819

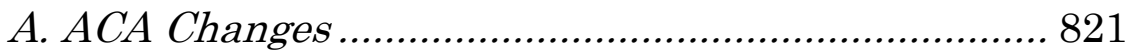

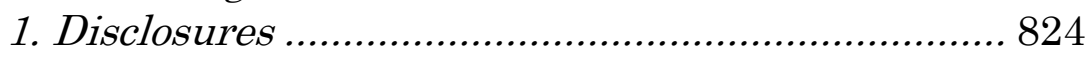

2. Bona Fide Investment......................................... 825

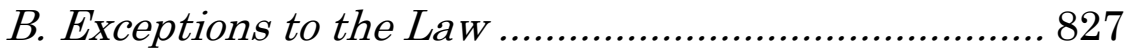

C. Physician Hospitals of America v. Sebelius............. 829

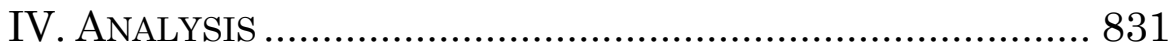

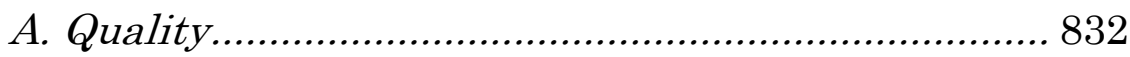

1. Focus Factories .................................................. 833

2. The Physician Knows Best ................................. 836

3. Name on the Door .............................................. 837

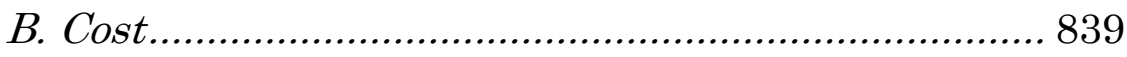

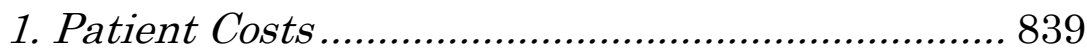

2. Sunk Costs for Physician Owned Hospitals.......... 841

3. Competition for Patients....................................... 843

4. Community Benefits ............................................ 844

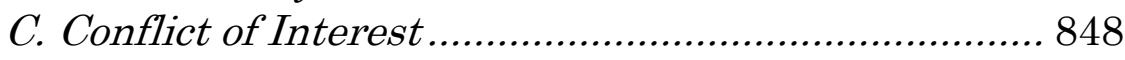

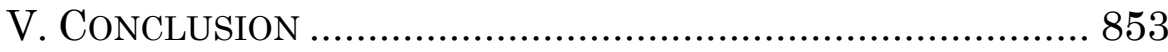

* J.D. Candidate, 2016, Indiana University Robert H. McKinney School of Law; M.B.A. Candidate, 2016, Indiana University Kelley School of Business; B.S., 2009, Purdue University. 


\section{INTRODUCTION}

OrthoIndy, a physician-owned group that owns Indiana Orthopaedic Hospital, ${ }^{1}$ announced in 2008 the opening of a new $\$ 20$ million dollar outpatient facility on the south side of Indianapolis. ${ }^{2}$ Unfortunately for OrthoIndy, the passage of the Affordable Care Act ("ACA") in 2010 altered its plans. Section 6001 of the ACA limits Medicare payments to physician-owned hospitals for services performed for Medicare patients referred by physician-owners. ${ }^{3}$ Existing physician-owned hospitals are grandfathered under the plan and allowed to continue to treat Medicare patients and receive payments. ${ }^{4}$ However, in order to expand a physician-owned hospital's existing facilities, a hospital must meet certain requirements to qualify for an exception and obtain permission from the Secretary of the Department of Health and Human Services ("HHS"). ${ }^{5}$ If the physician-owned hospital fails to meet these requirements but expands its facilities, the physician-owned hospital risks losing its Medicare payments. ${ }^{6}$ Medicare is the largest insurer in the United States, and loss of Medicare reimbursement payments would likely mean the physicianowned hospital must shut down. ${ }^{7}$ Because of the necessity

1 J.K. Wall, OrthoIndy Looks to Loopholes for Growth, INDIANAPOLIS Bus. J. (May 23, 2011), http://www.ibj.com/orthoindy-looks-to-loopholesfor-growth/PARAMS/article/27316 [hereinafter Loopholes].

2 OrthoIndy Planning Greenwood Center, InDianapolis Bus. J. (Dec. 11, 2008), http://www.ibj.com/orthoindy-planning-greenwoodcenter/PARAMS/article/10536.

342 U.S.C. $§ 1395 n n$ (2015); Physician Hosps. of Am. v. Sebilius, 691 F.3d 649, 651 (5th Cir. 2012).

${ }_{4}$ Physician Hosps. of Am., 691 F.3d at 652.

5 Id.

6 Ken Terry, Reform Law Cuts off Specialty Hospitals Just in Time to Prevent Explosive Growth, CBS NEws, http://www.cbsnews.com /8301-505123_162-43842312/reform-law-cuts-off-specialty-hospitalsjust-in-time-to-prevent-explosive-growth/ (last updated Jan. 4, 2011, 7:25 PM).

7 J.K. Wall, IU Health Buying Docs in Hospital Ventures, INDIANAPOLIS Bus. J. (May 23, 2011), http://www.ibj.com/iu-buying-out- 
of Medicare payments and the money they had already spent on the new facility, OrthoIndy eliminated four beds at its Indiana Orthopaedic Hospital in order to open four operating rooms in the new facility in March $2011 .{ }^{8}$

\section{A. The Issue}

By barring new physician-owned hospitals from obtaining Medicare certification, the ACA effectively bans the creation of new physician-owned hospitals. ${ }^{9}$ The ACA also drastically restricts the expansion of current physicianowned hospitals. ${ }^{10}$ The American Medical Association and other related medical organizations support physicianownership of hospitals because physician-owned hospitals "introduce healthy competition to the marketplace, increase high-quality care choices for patients and give physicians an alternative to more traditional hospital employment arrangements." 11 The ACA's language not only targets specialty hospitals, but also multispecialty hospitals, acute care facilities, and community hospitals supported by practicing physician investors. ${ }^{12}$ This Note focuses mostly

docs-in-hospital-ventures/PARAMS/article/27315 [hereinafter IU Health].

8 Loopholes, supra note 1.

9 See Tanya Albert Henry, Physician-Owned Hospitals Seize Their Moment, AM. MED. News (Apr. 29, 2013), http://www.amednews.com/article/20130429/government/130429948/4/;

David Whelan, ObamaCare's First Victim: Physician-Owned Specialty Hospitals, FORBES (Apr. 5, 2010, 4:46 PM), http://www.forbes.com/sites/sciencebiz/2010/04/05/obamacares-firstvictim-physician-owned-specialty-hospitals/; Elise Dunitz Brennan \& Hilary L. Velandia, Do the PPACA Amendments to the Stark Whole Hospital Exception Mean the Evolution of a Two-Tier System?, 4 J. HEALTH \& LIFE SCI. L. 40, 47 (2010).

10 Henry, supra note 9.

11 David Glendinning, House Bills Would Lift Ban on PhysicianOwned Hospitals, AM. MeD. News (Mar. 31, 2011), http://www.amednews.com/article/20110331/government/303319996/8/.

12 Id.; Leigh Walton, Hospital Syndications: Opportunities and Options or Poised for Extinction?, 21 HEALTH LAW. 1 (2009), available at http://www.americanbar.org/publications/health_lawyer_home/health_0 3_publications_HealthLawyer_vol_21.html. 
on the specialty hospitals because of the lack of research on the other physician owned hospitals. Congress should repeal Section 6001 of the ACA providing for limits on physician-owned hospitals as Section 6001 does not serve the needs of patients by improving health care quality, lowing health care costs, or resolving any issues regarding conflicts of interest.

\section{B. Roadmap}

This Note discusses the effects of the ACA changes on physician-owned hospitals. Part II begins with a short history of physician-owned hospitals and then describes the effects of the Stark Law, the Medicare Modernization Act, and Federal Anti-Kickback Statutes on physician-owned hospitals. Part III examines Section 6001 of the ACA and its effects on physician-owned hospitals. Part III finishes with an examination of a lawsuit brought against HHS by Physician Hospitals of America and Texas Spine and Joint Hospital, and the reasons for the case's dismissal. Part IV analyzes the arguments for and against the existence and expansion of physician-owned hospitals, focusing on three major arguments: the quality of care provided by physicianowned hospitals, the effects of physician-owned hospitals on the cost of care, and the potential conflicts of interest involved in physician referrals to hospitals in which the physician has an investment interest. Physician owned hospitals provide outstanding quality healthcare at a lower cost and claims of potential physician conflicts of interest are grossly overstated. For these reasons Section 6001 should be repealed, allowing physician owned hospitals to compete in the market on even footing with community hospitals.

\section{BACKGROUND}

For the majority of America's existence, most physicians have practiced unaffiliated to an organization. ${ }^{13}$ But in the

13 Joshua E. Perry, A Mortal Wound for Physician-Owned Specialty Hospitals? The Legal and Ethical Prognosis for Market-Driven, 
20th Century, physicians began joining group practices for a variety of capital and business related reasons. ${ }^{14}$ Community hospitals formed and began providing a wide range of services, and the government began requiring hospitals to provide some unprofitable services for the community good. ${ }^{15}$ Government regulations were also developed to prohibit hospitals from "dumping" unprofitable patients. ${ }^{16}$ Physicians began to seek new ways to have more control over the operations of the hospital because the physicians felt the community hospitals were unresponsive to the physicians' needs and ideas. ${ }^{17}$

In the 1980s, physician ownership of non-hospital facilities began expanding due to changes in the health care payment structure which caused doctors to pursue control over the facilities in which the physicians practice and new ways to supplement their incomes. ${ }^{18}$ By virtue of the physicians' ownership and management interests in these facilities, physicians could control the hiring of staff, which equipment to purchase, procedure schedules, and other

Entrepreneurial Medicine in the Wake of 2010 Health Care Insurance Reforms 1, $27 \quad$ (2010), http://papers.ssrn.com/sol3 /papers.cfm?abstract_id=1607029.

14 Id.

15 David A. Argue, An Economic Model of Competition Between General Hospitals and Physician-Owned Specialty Facilities, 52 ANTITRUst BULL. 347, 348 (2007).

16 Id. at 349; Emergency Medical Treatment and Labor Act (EMTALA), Centers For Medicare \& Medicaid Servs., https://www.cms.gov/Regulations-and-

Guidance/Legislation/EMTALA/index.html?redirect=/emtala (last visited Apr. 29, 2015) (EMTALA was enacted by Congress in 1986 in order to "ensure public access to emergency services regardless of ability to pay." Medicare-participating hospitals are required to provide a medical screening exam when requested to treat a patient with an emergency medical condition. Hospitals are then required to provide stabilizing treatment for patients with emergency medical conditions or transfer the patient if the hospital does not have the ability to stabilize the patient.).

17 Kathryn MacGregor, Specialty Hospitals: A Healthy Addition to the Healthcare Market?, 13 MicH. ST. J. MED. \& LAW 239, 241 (2009); Argue, supra note 15, at 349.

18 Patrick A. Sutton, The Stark Law in Retrospect, 20 ANNALS HEALTH L. 15, 17 (2011); Argue, supra note 15, at 349. 
hospital administrative decisions. In a community hospital, these are all choices that are made by the non-medical hospital administration. ${ }^{19}$ In efforts to control what the government believed to be conflicts of interest created by physician-ownership of these medical facilities receiving federal reimbursements, Congress implemented the Federal Anti-Kickback Statue, passed the Stark Law, and placed a temporary moratorium on physician-owned hospital creation with the Medicare Prescription Drug, Improvement, and Modernization Act. ${ }^{20}$

\section{A. Federal Anti-Kickback Statute}

The Medicare Anti-Fraud and Abuse Statute of 1972 ("Anti-Kickback Statute") created a criminal offense to offer, pay, or receive compensation for referrals for services that are reimbursed by any federal or state health care program. ${ }^{21}$ Violating the Anti-Kickback Statue can result in fines, imprisonment, or both and automatic exclusion from federal health care insurance programs. ${ }^{22}$ The AntiKickback Statute was intended to prevent providers from making medical decisions based on the physician's own selfinterest that could harm Medicare and Medicaid programs through increased costs and abusive practices. ${ }^{23}$ By preventing these decisions, the Anti-Kickback Statute aimed to "prevent overutilization, limit cost, preserve freedom of choice and preserve competition." 24 Congress

19 MacGregor, supra note 17, at 241 (Noting that physician productivity is increased when physician-owners control operations because there are fewer schedule disruptions, more efficient operating room turnover, and more control over operating room staff. This also improves productivity for non-owners who work in the hospital.).

20 See David W. Hilgers \& Sidney S. Welch, Physicians PostPPACA: Not Going Bust at the Healthcare Buffet, 24 HEALTH LaW. 1, 3 (2012); Walton, supra note 12.

2142 U.S.C. $\S 1320 a^{-7 b}$ (2015); Walton, supra note 12; Perry, supra note 13 , at 21 .

2242 U.S.C. $\$ 1320 \mathrm{a}-7 \mathrm{~b}(2015)$.

23 Guidance on the Federal Anti-Kickback Law, Program Assistance Letter 1995-10, Health Resources and Services Administration, http://bphc.hrsa.gov/programrequirements/policies/pal199510.html.

24 Id. 
instructed the HHS Office of Inspector General to promulgate rules to determine which actions would and would not constitute violations of the Anti-Kickback Statute, thereby creating safe harbors to allow for conduct that would benefit the health care system. ${ }^{25}$ Congress became concerned that the Anti-Kickback Statute and the safe harbors create by the HHS were not adequately curtailing fraudulent behavior in the health care system. ${ }^{26}$ Representative Fortney H. (Pete) Stark from California proposed legislation intended to broaden the prohibition of Medicare and Medicaid fraud. ${ }^{27}$

\section{B. Stark Law}

Section 1877 of the Social Security Act, ${ }^{28}$ commonly referred to as "the Stark Law," was passed in 1989 as a prohibition on physician referrals for laboratory services to an entity in which the physician has ownership interest. It was later was expanded to include many other services and other methods of compensation from medical facilities. ${ }^{29}$ Congress enacted this law after studies found that physicians with ownership interests in freestanding clinical laboratories, diagnostic imaging centers, or physical therapy centers ordered more services for patients than physicians with no ownership interest. 30

The Stark Law states that when a physician (or an immediate family member) has a direct or indirect ownership interest, investment interest, or compensation arrangement in a hospital, he is prohibited from referring a patient, covered by the Medicare program, for "designated

25 Perry, supra note 13, at 21.

26 Id. at 23.

27 Id. at 24 .

28 Michael O. Leavitt, Study of Physician-Owned Specialty Hospitals Required in Section 507(c)(2) of the Medicare Prescription Drug, Improvement, and Modernization Act of 2003, 1 (2005), http://news.heartland.org/sites/all/modules/custom/heartland_migration/ files/pdfs/19681.pdf.

29 Sutton, supra note 18 , at 15.

30 Leavitt, supra note 28. 
health services" to the entity unless an exception applies. ${ }^{31}$ Designated health services include services such as physical therapy, occupational therapy, radiology, providing durable medical equipment, providing nutrition equipment and supplies, providing outpatient prescription drugs, ambulance services, home infusion therapy, and inpatient and outpatient hospital services. ${ }^{32}$ However, if a physician's ownership or investment interest is in the "whole hospital" then the Stark Law's "whole hospital exception" applies. ${ }^{33}$ This exception allows physicians with an ownership or investment interest in a hospital to refer patients to that hospital as long as the referring physician has privileges to treat patients at the hospital and the referring physician's financial interest is in the whole hospital, not just a part of the hospital. ${ }^{34}$

\section{Medicare Modernization Act}

In response to a rising number of physician-owned specialty hospitals, Congress included restrictions on physician-owned hospitals in the Medicare Prescription Drug, Improvement, and Modernization Act of 2003 ("MMA"). ${ }^{35}$ For 18 months beginning on December 8, 2003, physicians were prohibited from referring Medicare or Medicaid patients to specialty hospitals in which the

3142 U.S.C §1395nn(a) (2015); Kathy L. Poppitt, Physician Ownership of Hospitals: Identifying and Dealing with the Restrictions, Options and Risks Following the Enactment of ACA and Recent Litigation,

http://www.coxsmith.com/portalresource/lookup/wosid/intelliun-105-

8302/media.name=/LIBRARY1Poppittpresentation.PDF.

32 Sutton, supra note 18 , at 22.

33 Walton, supra note 12.

34 Howard Fredrick Hahn \& Torri A. Criger, Health Care Reform's Impact on Physician-Owned Hospitals, J. Health CARE CoMPliance 63, $63 \quad$ (2010), http://www.huschblackwell.com/ /media/Files /BusinessInsights/BusinessInsights/2010/09/Health\%20Care\%20Reform s\%20Impact\%20on\%20PhysicianOwned\%20Hos_/Files/Health\%20Care \%20Reforms\%20Impact\%20on\%20PhysicianOwned\%20Hos_/FileAttac hment/100901_Hahn.pdf.

35 Physician Hosps. of Am. v. Sebilius, 691 F.3d 649, 652 (5th Cir. 2012). 
physician had an investment interest. ${ }^{36}$ This included referrals that previously were allowed under the "whole hospital" exception. ${ }^{37}$ The moratorium was meant to prohibit creation of new physician-owned specialty hospitals. ${ }^{38}$ On June 9, 2005, the Centers for Medicare and Medicaid Services ("CMS") suspended processing of specialty hospital Medicare enrollment applications, effectively extending the moratorium for an additional six months. ${ }^{39}$

Section 507 of the MMA required the Medicare Payment Advisory Commission ("MedPAC") and the Secretary of the Department of Health and Human Services ("HHS") to study physician-owned hospitals and report the results to Congress ("MedPAC report"). 40 Specifically, the MedPAC report examined physician-owners referral patterns; compared quality of care and patient satisfaction between physician-owned hospitals and community hospitals; evaluated the differences in uncompensated care between physician-owned hospitals and community hospitals; and assessed the relative exemption of community hospitals. ${ }^{41}$ MedPAC analyzed Medicare's cost reports and inpatient claims to determine the cost effectiveness of physicianowned hospitals and the incentives for patient selection. ${ }^{42}$ The results of this study are discussed throughout this Note.

\section{IMPLEMENTATION OF THE ACA}

Reforms in the past, including the Stark Law, have targeted physician־owned specialty facilities like cardiac,

36 Poppitt, supra note 31 , at 1.

37 Id.

38 Brennan \& Velandia, supra note 9.

39 Poppitt, supra note 31, at 1.

40 Leavitt, supra note 28, at i.

41 Id.

42 Report to the Congress: Physician-Owned Specialty Hospitals, MEDICARE PAYMENT ADVISORY COMMISSION vii (2005), http://medpac.gov/documents/reports/Mar05_SpecHospitals [hereinafter MedPAC Report]. 
orthopedic, or other surgical facilities that focus on a select few services. ${ }^{43}$ The reforms have focused on these facilities because the government believes that there is a financial incentive for physician-owners to refer patients to these owned facilities and to over-utilize procedures. The MedPAC report found that ownership had an effect (albeit a weak effect) on physician-owners referring patients to physician-owned specialty hospitals. ${ }^{44}$ There was a "mildly positive correlation between the size of the physician's ownership share and the percentage of his or her patients treated at the specialty hospital." 45 HHS also found that some hospitals had a difference in referral rates between physician-owners and non-owners, and some hospitals did not have referral rates without significant differences between physician-owners and non-owners. ${ }^{46}$

Section 6001 of the ACA eliminates the "whole hospital" exception for all physician-owned hospitals without Medicare provider agreements before December 31, 2010 and significantly limits the ability for physician-owned hospitals grandfathered under the law to expand and still receive Medicare reimbursements. ${ }^{47}$ These changes will likely lead to the elimination of physician-owned hospitals and deprive Americans of the innovations in medical procedure and efficient hospital administration practices that the entrepreneurial physician-owners develop.

43 Chris Silva, Physician-Owned Hospitals: Endangered Species?, AM. MED. NEWS (June 28, 2010), http://www.amednews.com/article /20100628/government/306289947/4/.

44 Argue, supra note 15 , at 351.

45 Leavitt, supra note 28, at 26; see also Argue, supra note 15, at 351; Ashley Swanson, Physician Ownership and Incentives: Evidence from Cardiac Care, 38 (2012) http://econweb.umd.edu/ davis leventpapers/SwansonPhysician.pdf ("[T]he results on physician share do not suggest that financial stake impacts cherry-picking behavior.").

46 Argue, supra note 15 , at 351 ; see Swanson, supra note 45 ("[F] or markets with specialized physician-owned hospitals, physician-owners have a strong preference for treating at their owned facility and that owner preferences over hospitals do not differ substantially from those of non-owners in how they vary with patient characteristics.").

47 Poppitt, supra note 31, at 4. 


\section{A. ACA Changes}

Section 6001 of the ACA prohibits the creation of new physician-owned hospitals and the expansion of grandfathered physician-owned hospitals by restricting the Stark Law whole hospital exception. ${ }^{48}$ Hospitals with a provider agreement in effect on or before December 31, 2010 and physician ownership on or before March 31, 2010 are grandfathered under the law. Being grandfathered under the law means that physicians with ownership are permitted to refer Medicare beneficiaries to the hospital without violating the Stark Law. ${ }^{49}$ However, physicianowned hospitals are prohibited from increasing the total number of beds, operating rooms, or procedure rooms from the number licensed on March 23, 2010, the day that ACA was enacted, the "baseline" number. 50 Procedure rooms include rooms where catheterizations, angiographies, angiograms, and endoscopies are performed but, as of now, do not include rooms where CT, PET, or other services not specifically listed in the bill are performed. ${ }^{51}$

CMS acknowledged that some states only license the number of beds and not the number of operating or procedure rooms. However, regardless of whether a state licenses the operating or procedure rooms, hospitals are prohibited from expanding the number of rooms without obtaining an exception. ${ }^{52}$ According to CMS's comments regarding the ACA amendments to the "whole hospital" exception, a hospital may convert beds into procedure rooms or procedure rooms to beds as long as the aggregate number does not increase above the baseline. ${ }^{53}$ If a hospital was in the process of expanding the number of beds and rooms on March 23, 2010 but the beds and rooms were not in existence on the date, the beds and rooms are not counted in

48 Brennan \& Velandia, supra note 9.

49 Hahn \& Criger, supra note 34, at 64.

50 Id.

51 Id.

52 Poppitt, supra note 31 , at 8.

5375 Fed. Reg 71800, 72243 (2010); Poppitt, supra note 31, at 12. 
the baseline capacity for the hospital. ${ }^{54}$ If the rooms and/or beds are not counted in the baseline, the hospital cannot use them without eliminating beds or rooms elsewhere. The monies spent on the process of expanding are therefore wasted and a sunk cost for the hospital.

Section 6001 encompasses any facility that has physician ownership, even if that ownership is less than $1 \% .55$ This includes acute care facilities, multispecialty hospitals, and community hospitals that physician-investors have financially assisted because the hospitals were struggling, although the literature generally discusses only the physician-owned specialty hospitals. ${ }^{56}$ Examples of community hospitals that have paired with physicianinvestors are St. Vincent's in Indianapolis, which partnered with physicians to build a heart hospital, and the Baylor Health System in Dallas, which opened a series of specialty hospitals. ${ }^{57}$ These community hospitals decided their best interests lied in partnering with physicians rather than fighting the physicians. By partnering with the physicians, the community hospitals still receive a portion of the profits that the hospital otherwise may have lost from competition with a separate physician-owned hospital competitor. The community hospital also gains the added expertise and input of the physician co-owners in processes and procedures to make the hospital more efficient, safer, and a more conducive workplace for the medical staff. About 20\% of Baylor's $\$ 3.5$ billion in annual revenue comes from its partially physician-owned specialty facilities.58 These community hospitals will be unable to expand their specialty facilities because, prior to the ACA's enactment, the community hospital made a business decision to pair with physician-investors to expand the hospital's medical practices. In freely competitive markets, more health care facilities may have joint-ventured with physicians if the ACA had not prohibited Medicare from extending provider

\footnotetext{
54 Poppitt, supra note 31 , at 8.

55 Silva, supra note 43.

56 Id.

57 Terry, supra note 6.

58 Id.
} 
agreements to new physician-owned specialty hospitals. ${ }^{59}$ By financially collaborating with physicians, community hospitals could have taken advantage of the physicians' expertise, funding, and loyalty. Instead, community hospitals will continue to be managed by the career administrators who draw large salaries to continue the status quo of building larger hospital empires by squelching the managerial competition and innovation that could control health care costs. ${ }^{60}$

In 2011 Indiana University Health began buying out physician-owners of some of its hospitals. ${ }^{61}$ These hospitals were located in growing communities around Indianapolis, and Indiana University Health wanted to be able to expand its facilities as needed to treat the expanding patient populations. ${ }^{62}$ Because the ACA prevents expansion of physician-owned hospitals, in order to have the option to expand, Indiana University Health had no choice but to undo its ownership relationship with the physicians. ${ }^{63}$ In a growing community, hospitals will necessarily need to expand to accommodate the citizens. Here, Indiana University Health had partnered with physicians for the physicians' skill and knowledge but, for the reason of being able to grow with the community, the hospital group had to sever that relationship. The ending of the agreement between the hospital system and the physicians will only be a detriment to the community in the long run because of the loss of the physician input. This buyout left Indiana Orthopaedic Hospital as the only majority physician־owned hospital in the Indianapolis area. ${ }^{64}$

These limitations on expansion created uncertainties for all physician-owned specialty hospitals in the process of expanding in 2010. For many hospital expansion projects

$59 \quad I d$.

60 Regina Herzlinger, Who Killed Health Care? AmericA’s \$2 Trillion Medical Problem - AND the Consumer-Driven Cure 62 (2007).

61 IU Health, supra note 7.

62 Id.

63 Id.

64 Id. 
and new physician-owned hospitals in development, but not completed by the deadline, these limitations resulted in sunk costs for hospitals beginning construction prior to the reveal of the language of the ACA legislation.65 New physician-owned hospitals and those in development, but not completed by December 31, 2010, fall under the scope of the Stark Law. Because of the inability to expand, physician-owned hospitals will ultimately disappear. Physicians will eventually sell their shares to community hospitals, like in the case of Indiana University Health, or the physician-owned hospitals will fail financially because the physician-owned hospitals are prevented from truly competing in the marketplace.

\section{Disclosures}

The ACA requires disclosures to create transparency at physician-owned hospitals. The government believes that receiving revenue through ownership or compensation agreements encourages overutilization of the services a facility provides and by disclosing the financial relationship, patients are given the opportunity to seek the service from another provider. ${ }^{66}$ The hospital must disclose the identities of all investors and the nature and extent of investment terms to HHS annually. ${ }^{67}$ Hospitals must also require each physician-owner or investor to provide, for patients being referred, disclosures of the referring physician's ownership or investment interest in the hospital as well as the treating physician's ownership or investment in the hospital. ${ }^{68}$ Physician-owned hospitals are required to disclose their status as a partially or wholly physicianowned hospital on all advertising and public websites. ${ }^{69}$

65 Physician Hosps. of Am. v. Sebelius, 691 F.3d 649, 652 (5th Cir. 2012); David Hogberg, ObamaCare Will Effectively Bar New PhysicianOwned Hospitals, InVESTOR's Bus. DAILY (Mar. 24, 2010, 7:25 PM), http://news.investors.com/032410-528337-obamacare-will-effectivelybar-new-physician-owned-hospitals.htm [hereinafter Hogberg Ban].

66 See Hilgers \& Welch, supra note 20, at 5.

67 Perry, supra note 13 , at 42.

68 Id.

69 Id. 
Hospitals may not require any physician with direct or indirect ownership interests to make or influence referrals or to generate business for the hospital. 70

Not only are disclosures required to inform patients of the financial interests of their treating physicians, further disclosures are required to inform patients of any potential safety concerns. If a physician is not available on the premises at all times, the hospital must inform patients and receive a signed acknowledgment form from each patient indicating the patient's understanding. ${ }^{71}$ If a physician is not always present on the premises, the patient may be put at risk if complications arise. The acknowledgment form makes sure that the patient is aware of this fact. The hospital must have the capacity to provide initial evaluation and treatment to all patients upon arrival and, when necessary, to transfer patients to hospitals with the capacity to treat the patient. ${ }^{72}$ Moreover, all disclosures must be made in time to give the patient enough time to "make meaningful decisions regarding the receipt of care . . ."”73 Disclosures are necessary to insure that patients are aware of potential conflicts of interest their physician may have and to inform patients of any potential safety concerns. The disclosures also give the patient the opportunity to seek the same services in another facility.

\section{Bona Fide Investment}

The ACA also seeks to "ensur[e] bona fide investment[s]."74 "Bona fide investments" means that the percentage of the total value of physician ownership or investment interests in the hospital does not exceed the percentage established on March 23, 2010, the "baseline percentage."75 CMS recognized that the bona fide

70 Poppitt, supra note 31 , at 5.

71 Id.

72 Id.

73 Hahn \& Criger, supra note 34, at 64.

74 Patient Protection and Affordable Care Act, Pub. L. No. 148, 124

Stat. 119, 685 (codified at 42 U.S.C. $§ 1395 n n(i)(1)(D)(2015)$ ).

75 Poppitt, supra note 31, at 5. 
investment level may fluctuate as long as the physician investment level stays at or below the baseline percentage of physician ownership established on March 23, 2010.76

In order to ensure that physician owners are not provided unethical incentives for patient referrals, limits are placed on the financial benefits of their ownership. Physicians must not be offered ownership or investment interests or the opportunity to purchase or lease hospital property with more favorable terms than those offered to non-physician owners or investors. ${ }^{77}$ The hospital or any of its owners or investors, directly or indirectly, may not provide financing or make a loan, guarantee a loan, make payment toward a loan, or subsidize a loan in any way for or related to any individual physician or group of physicians to acquire ownership or investment interests in the hospital. ${ }^{78}$ Returns must be distributed to the owners and investors in amounts directly proportional to the individual or organization's ownership or interest in the hospital. ${ }^{79}$ Physician owners and investors may not receive guaranteed receipt of or right to purchase any other hospital related business interests. ${ }^{80}$ These provisions were included to make sure that physician-owned hospitals cannot unethically influence their physicians to decide to refer patients to the facility for financial reasons. The ACA also prohibits increasing the aggregate percentage of physicianownership of physician-owned hospitals or an entity whose assets include the hospital, above the baseline percentage as of March 23, 2010. ${ }^{81}$ The percentage may drop below the baseline percentage, and physicians can buy and sell shares, but the total physician ownership percentage can never go above the baseline.
76 Id. at 8.
$77 I d$. at 6.
$78 \mathrm{Id}$.
79 Id.
$80 \mathrm{Id}$.
8142 U.S.C $\S 1395 \mathrm{nn}(\mathrm{h})(7)(\mathrm{D})(\mathrm{i})$ (2015). 


\section{B. Exceptions to the Law}

A physician-owned hospital can apply for an exception to the Stark Law to allow the hospital to expand its number of beds, operating rooms, or procedure rooms. ${ }^{82}$ Physicianowned hospitals can apply to HHS for one of two exceptions no more than once every two years and must wait for input from members of the community. ${ }^{83}$ In order to qualify for an exception as an applicable hospital, the hospital must (a) be located in a county with population growth over the last five years at 150 percent that of the state; (b) be located in a state with an average bed capacity less than the national average; (c) have a total percentage of Medicaid patients greater than or equal to the average percentage of Medicaid patients treated by all hospitals in the county; (d) not "discriminate against beneficiaries of Federal health care programs and [] not permit physicians practicing at the hospital to discriminate ...."; and (e) have an average bed occupancy rate greater than the average bed occupancy rate of the State. ${ }^{84}$ In order to qualify as a high Medicaid facility, a hospital (a) cannot be the only hospital in the county; (b) have, in the most recent three years, an annual percent of inpatient Medicaid admissions greater than inpatient Medicaid admissions for any other hospital in the county; and (c) cannot "discriminate against beneficiaries of Federal health care programs and [] not permit physicians practicing at the hospital to discriminate . . ." 85 These exceptions are both very strict and will be difficult, if not impossible, for any physician-owned hospital to achieve.

Another issue with the exception requirements is that the data used to demonstrate the Medicaid admissions data, which comes from the Healthcare Cost Report Information System ("HCRIS"), is not without its limitations. ${ }^{86}$ The data

82 Brennan \& Velandia, supra note 9.

83 Hogberg Ban, supra note 65.

8442 U.S.C. $\S 1395 \mathrm{nn}(\mathrm{i})(3)(\mathrm{E})(2015)$.

85 Id. $\S 1395 \mathrm{nn}(\mathrm{h})(3)(\mathrm{F})$.

86 CMS Issues Proposed Rule Affecting Physician-Owned Hospital Expansion Requests, Hall RENDER Killian Heath \& LyMan (July 16, 2014), http://www.hallrender.com/resources/article/1906/. 
does not include Medicaid managed care admissions and discharges, and hospitals not participating as Medicare providers in the three most recent fiscal years would not have their data included in the HCRIS. ${ }^{87}$ Because of its limitations, this data has prevented physician-owned hospitals from applying for exceptions the hospitals would otherwise be eligible for. ${ }^{88}$ In these cases, the community needs expanded facilities, but regulations prohibit physician-owned hospitals from growing to meet this demand. Consequently, patients suffer by having to wait longer than necessary for procedures because the facilities are not large enough to meet the community's demand. In the 2015 Final Rule, CMS allows for the use of Supplemental Data Sources only until revised hospital cost reports can include information on Medicaid Managed Care discharge data. 89 Also, the 2015 Final Rule amended the Fiscal Year Standard by bifurcating it into separate standards for Medicaid inpatient admissions data and average bed capacity and occupancy. The Medicaid inpatient admissions data is interpreted as the 12 -month period containing all the required information from the requesting hospital and all hospitals that the requesting hospital must compare itself. ${ }^{90}$ The average bed capacity and occupancy HCRIS data includes is the most recent fiscal year with enough data to determine the average bed capacity and bed occupancy for the state and the nation. ${ }^{91}$

Even if a hospital meets all the requirements and is granted an exception, the law prohibits the hospital from expanding more than 200 percent from its "baseline" number of beds, operating rooms, or procedure rooms, and the expansion may only occur on the hospital's main campus. ${ }^{92}$ The CMS's exception determination is prohibited

87 Id.

$88 I d$.

89 CMS Issues Amended Final Rule Impacting Physician-Owned Hospital Expansion Requests, HaLl RENDER KILLIAN HEATH \& LYMAN (Nov. 11, 2014), http://www.hallrender.com/resources/article/2027/.

90 Id.

91 Id.

92 Hogberg Ban, supra note 65; Hahn \& Criger, supra note 34, at 65. 
from review by any administrative or judicial proceedings according to the ACA. ${ }^{93}$

\section{Physician Hospitals of America v. Sebelius}

Because of these changes, Physician Hospitals of America and Texas Spine \& Joint Hospital jointly filed suit against Kathleen Sebelius, Secretary of the Department of Health and Human Services ("HHS Secretary"), in U.S. Federal Court for the Eastern District of Texas.94 The plaintiffs were seeking a declaratory judgment and injunctive relief from Section 6001 of ACA, alleging that the provision is unconstitutional because of a violation of due process and of equal protection rights and is void for vagueness. ${ }^{95}$

Physician Hospitals of America ("PHA") is an organization dedicated to supporting the interests of physician-owned hospitals. ${ }^{96}$ Texas Spine \& Joint Hospital ("TSJH") is a physician-owned hospital in Texas that, in 2008 prior to any discussion of or passage of the ACA, had decided to expand its facilities and had already invested $\$ 3$ million towards the $\$ 30$ million expansion. ${ }^{97}$

The district court denied the Secretary's motion to dismiss for lack of jurisdiction but found that Congress had a rational basis for passing Section 6001, that Section 6001 does not create a real or regulatory taking, and the requirements are not unconstitutionally vague. ${ }^{98}$ The plaintiffs appealed. The Fifth Circuit vacated the district court's decision and dismissed the action because the court found that the federal courts lacked subject matter jurisdiction. ${ }^{99}$ The court found that the claims arose under the Medicare Act, which requires that all legal claims be

93 Poppitt, supra note 31, at 7.

94 Physician Hosps. of Am. v. Sebilius, 691 F.3d 649 (5th Cir. 2012).

95 Id. at 652.

96 Id.

$97 \mathrm{Id}$.

98 Id. at 651.

99 Id. at 659. 
presented first to the HHS Secretary. ${ }^{100}$ Title 42, Section 1395ii substitutes the HHS Secretary for the Social Security Commissioner in 42 U.S.C. $\S 405$ (h) and, in doing so, making Section 405(g) applicable to Medicare claims. ${ }^{101}$ Only after the HHS Secretary renders a final decision can a party to the administrative proceeding "obtain a review of such decision by a civil action ...."102 This failure to pursue first an administrative proceeding left the district court without subject-matter jurisdiction over the claim. ${ }^{103}$ Only by experiencing a "complete preclusion of judicial review" will a party be able to litigate its claims in federal court without having to fulfill the requirement to seek administrative proceedings. ${ }^{104}$

The plaintiffs argued that the Illinois Counsel exception applied in this case. In Shalala v. Illinois Council on Long Term Care, Inc., the Court concluded that Section 405(h) does not apply when application "would not simply channel review through the agency, but would mean no review at all."105 This means that the party would be unable to complete the administrative requirements in order to receive an administrative ruling. Without an administrative ruling, the party could not appeal to the court system for judicial review. The plaintiffs argued that the Illinois Council exception applies because the administrative proceeding "would result in the practical denial of judicial review." 106 The plaintiffs would have to complete construction on the hospital expansion, treat a patient in the new facilities, be denied the claim for Medicare reimbursement, file the administrative claim with the HHS Secretary, and be denied again (possibly risking losing Medicare reimbursements on the existing facility) all before the hospitals are able to bring the claim in federal

100 Id. at 653.

101 Id. at 659.

10242 U.S.C. $\$ 405(\mathrm{~g})$ (2015).

103 Physician Hosps. of Am., 691 F.3d at 653.

104 Id.

105 Shalala v. Ill. Council on Long Term Care, Inc., 529 U.S. 1, 19 (2000)

106 Physician Hosps. of Am., 691 F.3d at 656. 
court. ${ }^{107}$ The court rejected this argument because the courts are not concerned with whether the instant plaintiffs are unable to bring their claim, but whether no one may bring the claim leaving "no other path for judicial review."108 "A party may not circumvent the channeling requirement by showing merely that "postponement of judicial review would mean added inconvenience or cost in an isolated, particular case."'109 While another physicianowned hospital could possibly bring this claim against the HHS Secretary, that hospital will have the same issues as Texas Spine \& Joint. The physician-owned hospital will have spend money to build a facility to completion so that the hospital can treat a patient, bill Medicare for reimbursement, have the reimbursement request rejected, and go through the Medicare Act administrative proceedings all before the hospital can file a claim in court. The Illinois Council exception should apply in this case so that physician-owned hospitals can have their claims heard by an impartial court. Without the exception, the physician-owned hospital industry will never be able to have their concerns heard and ruled upon.

\section{ANALYSIS}

When the ACA was passed in 2010 there were 265 physician-owned hospitals in the United States, but four years later that number has dropped to 238.110 The over$10 \%$ drop is proof that Section 6001 has upset the physicianowned hospital industry. In the mean time, the CMS has released the data for its new Hospital Value Based Purchasing Program that ranks 3428 hospitals nationally based on the hospital's quality. ${ }^{111}$ Physician-owned hospitals claim 9 of the top 10 spots and 48 of the top 100

107 Id.

108 Id.

109 Id. at 657 (citing Council for Urological Interests v. Sebelius, 668 F.3d 404, 708 (D.C. Cir. 2011)).

110 Henry, supra note 9.

111 Letter from John W. Dietz, Jr., (Nov. 13, 2013) (on file with author). 
spots, even though physician-owned hospitals comprise only 196 of the 3428 ranked hospitals in the nation. ${ }^{112}$ Indiana Orthopaedic Hospital in particular is ranked eleventh in the country by the CMS Hospital Value Based Purchasing Program. By eliminating the ability of physician-owned hospitals to expand and therefore to compete on a level playing field with non-physician-owned hospitals, Section 6001 of the ACA negatively affects the quality of care, cost of care, ${ }^{113}$ and falsely accuses physician-owned hospitals of conflicts of interest.

\section{A. Quality}

There are three ways quality is improved in physicianowned specialty hospitals: the hospitals are "focused factories," the physician "knows best," and the physician's "name is on the door." 114 Patient outcomes are improved in physician-owned specialty hospitals because the physicians and hospital staff are able to focus on a limited range of diagnoses and procedures. ${ }^{115}$ Thirty-day risk-adjusted mortality rates are "significantly lower for specialty hospitals than for community hospitals."116 Furthermore, studies have shown that hip and knee replacement surgeries at orthopedic hospitals, such as Indiana Orthopaedic Hospital, result in a 50\% lower complication

112 Id.

113 Spencer Harris \& Brad Zarin, Physician-Owned Hospitals, TEX. PuB. POL'Y FOUND. 1, 5 (2011), http://www.texaspolicy.com /center/health-care/reports/physician-owned-hospitals.

114 Swanson, supra note 45, at 8 (Physician-owned specialty hospitals are "focus factories" because the hospital has equipment, staff, and management dedicated and tailored to the particular specialty; the physician "knows best" because he has input in the design of the facility and procedures; and because the physician has his "name on the door" he has a greater interest in the hospital's overall reputation. These three things imply high quality, low cost care.).

115 Leslie Greenwald et al., Specialty Versus Community Hospitals: Referrals, Quality, and Community Benefits, 25 HeALth AFF. 106, 112 (2006).

116 Id. at 113; Swanson, supra note 45, at 1 (Physician-owned hospitals show evidence of significant mortality improvement, primarily for moderate severity patients). 
rate than at community hospitals. ${ }^{117}$ The specialization of the physicians, nurses, and medical staffs at physicianowned specialty hospitals creates a team that is made up of experts in the hospital's particular field. ${ }^{118}$ Also, physicianowned specialty hospitals staff more nurses per bed than community hospitals.119 By employing experts in the specialty at every level of care, the hospital is best able to efficiently treat the patient and prevent any common complications that may arise from the procedure.

\section{Focus Factories}

Patients benefit from lower cost and better quality care created through physician innovation and specialized care. Physician-owners are reimbursed for their extra effort of medical procedure innovation and hospital management roles with a portion of the value that each physician produces for the hospital. The focus on a limited range of services provided by physician-owned specialty hospitals has been shown to increase positive outcomes and decrease complications. ${ }^{120}$ In Texas for example, when physicianowners of cardiac specialty hospitals treat patients in community hospitals the morality rate is significantly higher than the risk-adjusted in-hospital mortality rate at specialty hospitals. ${ }^{121}$ This shows that the specialization of the hospital and extra attention by the physician-owners and managers in implementing procedures, hiring staff, and purchasing equipment makes a difference in the quality of care provided. The physician is not the only person treating the patient; having the most qualified team and the safest hospital procedures clearly impacts the quality of care.

Opponents of physician-owned hospitals question the reliability of the risk-adjusted in-hospital morality rate

117 Dietz, supra note 111.

118 HERZLINGER, supra note 60, at 3.

119 Liam O'Neill \& Arthur J. Hartz, Lower Mortality Rates at Cardiac Specialty Hospitals Traceable to Healthier Patients and to Doctors' Performing More Procedures, 31 Health AfF. 806, 807 (2012).

120 Henry, supra note 9.

121 O'Neill \& Hartz, supra note 119, at 806. 
difference. While the patient outcomes of physician-owned hospitals appear to be better than those of community hospitals, opponents of physician-owned hospitals believe evidence of physicians choosing healthier patients and those with fewer co-morbidities can account for the differences in outcomes. ${ }^{122}$ Peter Cram found that the differences in riskadjusted outcomes were not significant once the study accounted for patient severity and hospital volume. ${ }^{123}$ However, in later studies when different risk-adjustment models are used the opposite conclusion is reached. ${ }^{124}$

Critics also believe that physician-owned specialty hospitals create safety issues for patients. ${ }^{125}$ Opponents of physician-owned hospitals claim that by offering a limited range of procedures, physician-owned specialty hospitals are not equipped to appropriately deal with complications. ${ }^{126}$ Physicians have an ethical and legal duty to "do no harm" to their patients and a professional mandate to put their patient's interests above the physician's own interests, not to choose to operate in a facility because of the physician's economic self-interest. 127 If the facilities cannot adequately treat the patient, including any emergency conditions, then physician-owners referring to their owned facilities are not fulfilling the physicians' duty to their patients, but instead are looking out only for their personal gain.

Issues arise for physician-owned specialty hospitals when the hospitals are not staffed with physicians at night or when the employees do not have the emergency training or the emergency equipment to deal with medical crises. In a medical crisis, the staff at the physician-owned hospitals may have to resort to calling 9-1-1 for help. Opponents of physician-owned hospitals use stories of patients who have lost their lives at physician-owned specialty hospitals because the hospitals did not have the full services to

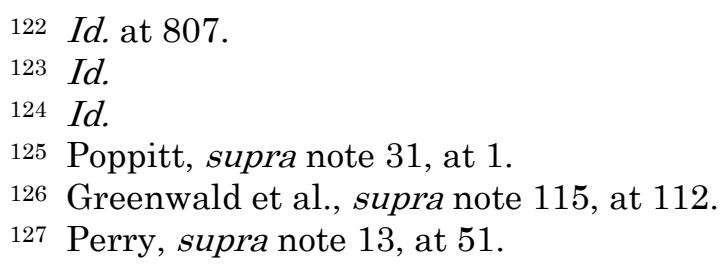


combat emergency situations that arose during treatment to illustrate their point. ${ }^{128}$ Most of the hospitals in these examples did not have physicians or trained emergency personnel on hand and had to resort to calling emergency medical services for transportation to the nearest general hospital, too late to save the patient's life. ${ }^{129}$ This lack of emergency equipment and training can pose a significant problem for safety at physician-owned hospitals.

Some interpret the lower severity levels in physicianowned specialty hospitals as "cherry picking," but the MedPAC report also argues that the lower severity levels could be considered to be a quality indicator. ${ }^{130}$ By focusing on a particular patient type, these hospitals can adequately treat patients with the best care. ${ }^{131}$ There are other reasons that could account for different patient severity levels too. The demographics and health characteristics in the community surrounding the hospital location may play a role. Also, "optimal matching," where "different hospitals may be better suited to treating different types of patients," may affect a physician's referral decision and therefore a hospital's outcomes. ${ }^{132}$ An example of this would be a cardiac patient with a non-cardiac illness such as diabetes who would be best treated in a full-service community hospital as opposed to a specialized cardiac hospital. This patient may need treatment by multiple specialists, making a general hospital a better facility for the procedure. According to Dr. John Dietz, orthopedic surgeon and part owner of Indiana Orthopaedic Hospital, the only reasons physicians practicing at Indiana Orthopaedic Hospital would send a patient to another hospital are because the insurance will not cover treatment at Indiana Orthopaedic Hospital, the patient wants to be treated at another

128 Id. at 2-6.

129 Id.

130 Leavitt, supra note 28, at 61 ; see Swanson, supra note 45 , at 1 ("[T]here is no strong evidence of physician-owner cherry-picking of healthier patients. The distribution of patients across hospitals is primarily driven by physicians' average preferences over hospitals.").

131 Leavitt, supra note 28, at 61-62.

132 Swanson, supra note 45 , at 2-3. 
location, or the patient's primary-care physician prefers another hospital. ${ }^{133}$ Otherwise, all patients would be treated at Indiana Orthopaedic Hospital. Physician-owners have a preference for treating their patients at the hospital where the physicians have helped designed the facilities, procedures, and staff to be exactly what the physicians believe are best for their combined practice. ${ }^{134}$

\section{The Physician Knows Best}

Physician-owned hospitals have proven to be more efficient and less bureaucratic than community hospitals. ${ }^{135}$ When physicians own the hospital in which they work, the physicians are able to design and operate the hospital in a way that overcomes the inadequacies the physicians experienced in community hospitals. ${ }^{136}$ In order to combat a dangerous complication of heart surgery, one specialty cardiology hospital developed a new standard protocol which reduced the occurrence of such complications by twothirds. 137 This kind of innovation is less likely to happen at a large community hospital, so having smaller, more nimble physician-owned facilities is important to the overall market for testing new procedures to improve care. Physician-owners in physician-owned specialty hospitals also govern the hospital, eliminating the issue of traditional hospital administration making unilateral decisions that the physicians feel harm productivity and patient care. 138 With fewer layers of bureaucracy, changes can be made in physician-owned hospitals more quickly than at community hospitals, thus making physician-owned hospitals more responsive. ${ }^{139}$

\footnotetext{
133 Hogberg Ban, supra note 65.

134 See Swanson, supra note 45 , at 35 .

135 Dietz, supra note 111.

136 HERZLINGER, supra note 60, at 76.

137 Id.

138 Id. at 77.

139 Henry, supra note 9.
} 


\section{Name on the Door}

When physicians own a portion of the hospital where they are employed, the physicians have a commitment to and pride in the organization that is not replicated in community hospitals. ${ }^{140}$ According to the Physician Hospitals of America's former executive director, Molly Sandvig, physicians opened their own hospitals "because they want[ed] to do something right by their patients. They want[ed] to be able to control health care, and they [did not] feel like they [could] do that at community facilities any more." ${ }^{141}$ By having an interest in the owning and operating of the hospital, physicians have a "sense of responsibility for the outcomes." 142 Physician-owners must be concerned with the mortality and morbidity outcomes of their hospital in addition to their personal procedure outcomes. This concern give them an extra reason to make sure that they, the other physicians practicing at the facility, and their hospital staff are the most qualified care providers and that the physician-owned hospital's processes ensure the most safe and efficient patient care possible.

Physicians should be allowed and empowered to create better quality, less expensive care. "Physician-owned hospitals provide high-quality patient care and increase competition and choice in the marketplace -- those should be the hallmarks against which these hospitals are judged, said then-AMA President J. James Rohack, MD.”143 "Restricting physician-owned hospitals is counter to what we are working to achieve: a better health care system for patients and physicians." 144

Data from the research study conducted by Leslie Greenwald shows that there is little difference in the referral patterns of physician-owners and non-owners. ${ }^{145}$ This data would suggest that the referring physicians are

\footnotetext{
140 Greenwald et al., supra note 115, at 117.

141 Silva, supra note 43.

142 Henry, supra note 9.

143 Silva, supra note 43.

144 Id.

145 Greenwald et al., supra note 115, at 112.
} 
primarily concerned with the specialization of the hospital and not the ownership when choosing a facility to refer their patients. ${ }^{146}$ The MedPAC report postulated that "[a] hospital that accepts patients that it cannot properly treat may not exhibit good quality healthcare."147 A physician who has taken an oath to "do no harm" is under an obligation to make the decision of where to treat in the best interest of his patient. Referring a patient to a facility that cannot properly treat is not in the best interest of the patient and therefore is not something a physician would do.

The ACA's Hospital Value Based Purchasing Program rewards hospitals for providing quality care to patients. ${ }^{148}$ Hospital quality is measured using metrics for hospital process and patient satisfaction. ${ }^{149}$ At the end of 2012, HHS announced the first set of hospital bonuses and penalties for the Hospital Value Based Purchasing Program. Nine of the top ten hospitals and forty-eight of the top one hundred hospitals ranked by HHS were physician-owned hospitals. ${ }^{150}$ These rankings back up the HHS findings in its 2005 study that physician-owned specialty hospitals "provide a high level of quality of care."151 This provides proof, from the very administration limiting physicianowned hospital growth, that physician-owned hospitals have more focus on patient care and have better processes due to smaller administrations and fewer bureaucratic layers to get to quality at the patient bedside.

146 Id.

147 Leavitt, supra note 28, at 61.

148 David Hogberg, Op-Ed: Congress Should Repeal Limits on New Doctor-Owned Hospitals, WASH. ExAMINER (Mar. 6, 2013, 12:00 AM), http://washingtonexaminer.com/op-ed-congress-should-repeal-limits-onnew-doctor-owned-hospitals/article/2523441 [hereinafter Hogberg Repeal].

149 Id.

150 Id.

151 Leavitt, supra note 28, at 62. 


\section{B. Cost}

Health care costs made up $17.1 \%$ of the United States GDP in 2013, a continuation of the health care cost growth trend. ${ }^{152}$ These costs put an enormous strain on federal and state government budgets as well as individual families. Part of the purpose of the ACA was to remedy these cost increases. However, instead of slowing the growth of health care costs, the physician-owned hospital provisions of the ACA actually increase costs by discouraging community hospitals from increasing cost efficiency, creating sunk costs for some physician-owned hospitals, and limiting community benefits from the taxes paid by physician־owned hospitals.

\section{Patient Costs}

A patient's fees provide two streams of revenue. ${ }^{153}$ One goes to the physician as a professional fee for his service. The other is a facility fee that is paid to the hospital for use of the operating room, hospital bed, nursing staff, and other items provided by the hospital. The hospital's facility fee eclipses the physician's professional fee and makes up the majority of the cost to the patient. ${ }^{154}$

Opponents of physician-owned hospitals believe that physician-owned hospitals contribute to the health care cost problem. The opponents claim that the physician-owned hospitals "cherry-pick" the most lucrative patients by referring the healthier patients or the ones needing more profitable procedures to the physician's owned facility for financial gain while sending less lucrative patients to community hospitals. 155 Physician-owners share in the profits of the hospital, giving the physicians a financial incentive to increase profits. By referring the easier

152 Health Expenditure, Total (\% of GDP), WORLD BANK, http://data.worldbank.org/indicator/SH.XPD.TOTL.ZS (last visited Apr. $30,2015)$.

153 Whelan, supra note 9.

154 Id.

155 Leavitt, supra note 28, at 2. 
patients to physician-owned facilities, the physicians can increase the net income of the hospital which is then distributed to the owners or reinvested back into the hospital.156 Opponents also argue that compensation schemes for physicians can incentivize the physicians to over-utilize hospital diagnostic tests, services, and procedures. Many believe that without some checks on the growth of specialty hospitals, community hospitals will find large declines in profit margins. 157

The 2005 MedPAC report revealed that "physicianowned specialty hospitals do treat a higher percentage of patients who are less sick, and therefore less costly and more profitable, than patients receiving similar treatments at general hospitals." 158 According to the 2005 MedPAC report, $1 \%-2 \%$ of patients admitted to specialty hospitals have Medicaid compared to $15 \%$ at community hospitals. 159 The study also found that most of the patients treated at physician-owned specialty hospitals come from the potential patient pool for the community hospitals, taking market share away from the community hospitals. ${ }^{160}$ Liam O'Neill and Arthur J. Hartz found that in Texas between 2004 and 2007 the "risk-adjusted in-hospital mortality rate for patients treated at specialty hospitals in the state was significantly below the rate for all hospitals in the state... " but "the rate was significantly higher when physicians who owned cardiac specialty hospitals treated patients in general hospitals . . ."161 This could indicate that physician-owners are referring healthier patients to the physician-owned facilities. One study that examined

\footnotetext{
156 Id.

157 Perry, supra note 13, at 34.

158 Id.

159 Orthopedic Specialty Hospitals Promise Better Care, But May Face Ethical Dilemmas, ORTHOPEDICS TODAY (July 2012), http://www.healio.com/orthopedics/business-oforthopedics/news/print/orthopedics-today/\%7B5e3b9ade-c0a4-46c59493-f4459bf57c49\%7D/orthopedic-specialty-hospitals-promise-bettercare-but-may-face-ethical-dilemmas [hereinafter Orthopedic Ethical Dilemmas].

160 Perry, supra note 13 , at 34 .

161 O’Neill \& Hartz, supra note 119, at 806.
} 
referral patterns of physician-owners found that physicianowners referred healthier and more profitable patients to the hospitals the physicians owned. 162 By taking away the lucrative patients from the community hospital, the community hospitals lose revenue that the hospitals would use to fund unprofitable services like emergency rooms or burn units.

While physicians may have an interest in increasing the profits of the hospital, profits are not likely to be physicians' first priority. Most individual physicians own small proportions of the physician-owned hospitals so each physician's share of the hospital profits are small as well. ${ }^{163}$ As previously stated in this Note, each investor receives a portion of the profits proportional to its ownership position. The investors must also rely on the other physicians with privileges at the physician-owned hospital to provide value for the hospital because all the physicians share in the profits. Generally, each physician receives a share of all the profits of all the patients, not just his own. ${ }^{164}$ Also, opening a hospital takes a large initial capital expenditure and recouping that amount takes several years. This means that the hospitals will not be returning profits to investors for a few years after beginning operation. After waiting a few years for income from the investment and receiving such a small portion, a physician would not be motivated to cherry pick patients or over-utilize services.

\section{Sunk Costs for Physician Owned Hospitals}

Proponents of physician-owned hospitals claim that the ACA's requirements to meet an exception are so arduous that the requirements are impossible to meet. ${ }^{165}$ Texas Spine and Joint Hospital had a $\$ 37$ million project to add three operating rooms, three procedure rooms, and twenty beds to its facility. ${ }^{166}$ This expansion would have doubled

\footnotetext{
162 Id. at 807.

163 Argue, supra note 15, at 350.

164 Id.

165 Henry, supra note 9.

166 Silva, supra note 43.
} 
capacity and provided about 540 new jobs for the local community. ${ }^{167}$ In a time of a suffering job market, these jobs would have been a great boost to the local economy. In Loma Linda, California, physician investors were working with the local university's medical center to develop a 110 bed tower and medical office building as part of a $\$ 250$ million project. 168 The building would have provided care to areas underserved in the community, but the new building was abandoned because the new facility would not have had Medicare certification by the deadline. ${ }^{169}$ Dr. John Piconi, retired urologist and lead of the physician-investors in the project, said "We started this project four years ago when there was no law prohibiting us from doing [it]."170 Indiana Orthopaedic Hospital's investors had put $\$ 27$ million into a new building with three rooms for outpatient surgery that was three-quarters finished and was almost unable to be used. ${ }^{171}$ These expansions take years to plan and complete and were all started long before discussions began on the ACA. The capital loss to the hospitals and the loss of availability of quality care to the communities when the hospitals had no warning of the existence of or extent of the regulations is reprehensible.

These entrepreneurial physician groups are not the only ones affected by the changes to the Stark Law. Over sixty hospitals under development before the passing of the ACA were essentially destroyed by Section 6001.172 "[A]t a time when the government is supposedly attempting to increase access to care, it has chosen to stop the growth of many of the best hospitals in the country," said Molly Sandvig, former PHA executive director. ${ }^{173}$ While politicians were promising more "shovel ready" jobs for struggling communities, the same politicians were actively prohibiting the creation of construction, medical, custodial,

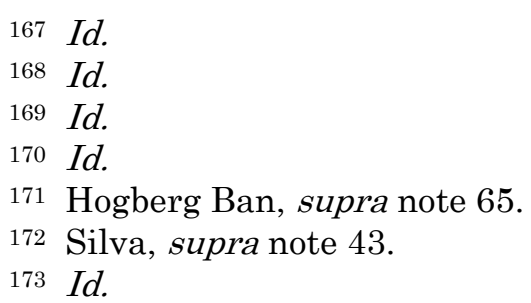


administrative, and other jobs that would definitely materialize because of these hospital creations and expansions. The physician-owned hospitals that are grandfathered under the law and still able to operate are prohibited from expanding, even in cases where the physician-owned hospitals have spent considerable amounts on expansions that were planned long before ACA was passed. ${ }^{174}$ This is a huge waste of capital resources for the hospitals. Had the hospitals been given sufficient warning, the funds the physicians expended on hospital expansion projects that have had to be cancelled could have been used instead to update equipment, provide uncompensated care to the uninsured, or other productive uses.

\section{Competition for Patients}

Physician-owned hospitals also compete with community hospitals for patient market share. In December 1996, St. Luke's, an ambulatory surgery center, opened. ${ }^{175}$ St. Luke's is owned by physicians on the staff of North Oaks, the only full-service acute care hospital in Hammond, Louisiana. 176 While North Oaks inpatient procedure volumes stayed about the same, its outpatient surgery volume dropped. According to the authors, St. Luke's outpatient volume rose "sharply" in 1997, while North Oaks saw a corresponding drop during the same time period. 177 The authors argue that the threat to community hospitals is due to competition lowering prices in the market and a loss of patient volume in the community hospital. ${ }^{178}$ While on the surface it looks to be procompetitive to open a new hospital and expand

174 See Physician Hosps. of Am. v. Sebilius, 691 F.3d 649, 652 (5th Cir. 2012); Loopholes, supra note 1; Silva, supra note 43.

175 William J. Lynk \& Carina S. Longley, The Effect of PhysicianOwned Surgicenters on Hospital Outpatient Surgery, 21 HeAlth AFF. 215, 216 (2002).

176 Id.

177 Id.; see Argue, supra note 15, at 352 ("[T]he increase in specialty facility patient volume mirrors the decrease in patient volume at the competing hospital, at least initially.").

178 Lynk \& Longley, supra note 175, at 221. 
overall market output, the authors believe that the competition effects are clouded by physician-owners financial incentives. ${ }^{179}$

What the authors failed to point out is that any increase from a baseline of 0 surgeries will appear to be a sharp increase in a market with a fixed number of patients. While North Oaks experienced a temporary drop in outpatient surgical procedures in 1997, by mid-1998 its volume returned to the pre-St. Luke's level. ${ }^{180}$ In Exhibit 1, the hospitals received corresponding increases and decreases in surgical volumes during 1997.181 In 1999 St. Luke's experienced an increase in surgical procedures, but the decrease that North Oakes experienced was much less than St. Luke's increase. This shows that there were plenty of patients for both hospitals to treat. When a new competitor enters the marketplace, some customers will move to the new competitor from the old competitor. However, since the overall volume of outpatient surgical procedures continues to increase, there is clearly a large enough population of patients to support both hospitals. The number of cases referred to North Oakes by physician-owners decreased after the opening of St. Luke's. As discussed elsewhere in this Note, physician-owners opened their own hospitals and refer patients to their owned facilities because the physicians believe that treatment at the hospital that they helped design and run is in the best interest of their patients. For a physician-owner to refer his patients to his owned facility is not an unusual or unreasonable occurrence because he believes that his facility provides the best care. He helped chose the nursing and medical staffs, helped pick out the equipment, and had input on the procedures used in the hospital. If he did not believe that his hospital was the best location for treatment, the physician would not have taken the financial risk to invest in it.

\section{Community Benefits}

179 Id.

180 Id. at 216.

181 Id. 
While the MedPAC report discussed earlier found that a smaller percentage of Medicaid patients are treated at specialty hospitals, the MedPAC report found no evidence that specialty hospitals are putting community hospitals out of business. 182 Specialty hospitals tend to make more in profit overall, but there is not a significant difference in the profitability of community hospitals that compete with specialty hospitals and those that do not. ${ }^{183}$ Competition from specialty hospitals actually encouraged and allowed community hospitals to improve hospital services and become more efficient. ${ }^{184}$ With the ACA providing insurance for an estimated 30 million people, the ability of physician-owned hospitals to provide efficient and low cost quality health care should not be stifled. ${ }^{185}$

The claim by opponents that, by treating the healthier patients, physician-owned hospitals make more profit per patient than community hospitals is inaccurate. Hospitals are reimbursed by Medicare based upon Diagnosis Related Groups ("DRGs"). 186 Using risk adjustments, patients with similar risks are grouped in one DRG. ${ }^{187}$ More severe health conditions, called co-morbid conditions or major comorbid conditions, qualify a patient's care for greater Medicare reimbursement. ${ }^{188}$ The CMS Value Based Purchasing database for Indianapolis-area hospitals performing the procedures commonly performed at Indiana Orthopaedic Hospital shows how Medicare charges vary between hospitals within the same DRG. For example, for a hip and knee replacement, which has the most standardized technique of all DRGs reported, the Medicare certified charges to the average non-physician owned hospital in the Indianapolis-area is $56 \%$ higher than the Indiana Orthopaedic Hospital. ${ }^{189}$ The excess charges for a procedure

\footnotetext{
182 Orthopedic Ethical Dilemmas, supra note 159.

183 MedPAC Report, supra note 42, at 15.

184 Orthopedic Ethical Dilemmas, supra note 159.

185 Henry, supra note 9.

186 Dietz, supra note 111.

187 Id.

188 Id.

189 Id.
} 
with a standardized technique are due in part to inefficiencies in the hospitals. ${ }^{190}$ Dr. Dietz said "[q]uite contrary to the provisions of Obamacare, we should be promoting the model of physician-ownership as an opportunity to create high-quality, highly efficient hospitals where Medicare recipients can get the best possible care at the least cost."191 A hospital with better staffing, organization, and less bureaucracy can complete surgeries up to $50 \%$ faster, thus decreasing the inefficiency costs. 192 Dr. Dietz says that the CMS data reflects the "wide variation in efficiency between hospitals in our HRR as well as the high degree of efficiency at [Indiana Orthopaedic Hospital]."193 If the five reported DRGs were performed at Indiana Orthopaedic Hospital, or a hospital with similar efficiencies, Medicare would have saved nearly $\$ 15$ million in payments in one HRR in one year and avoided the extra costs of complications by benefitting from the $50 \%$ lower complication rate. ${ }^{194}$ The CMS data support the idea that physician-owned hospitals should be allowed to open, exist, and expand to challenge community hospitals to improve efficiencies and provide better quality at lower cost.

Community hospitals have used their deep pockets to lobby representatives in the United States Congress to pass laws aimed at squelching their competitors, the physicianowned hospitals, and to award tax-exemptions. ${ }^{195}$ The community hospitals claim to need the tax exemptions in order to provide care for the poor and uninsured.196 However, these same hospitals charge uninsured patients prices much greater than those charged to insured patients. 197 The monies saved through these tax exemptions are not being passed onto the uninsured through lower hospital prices.

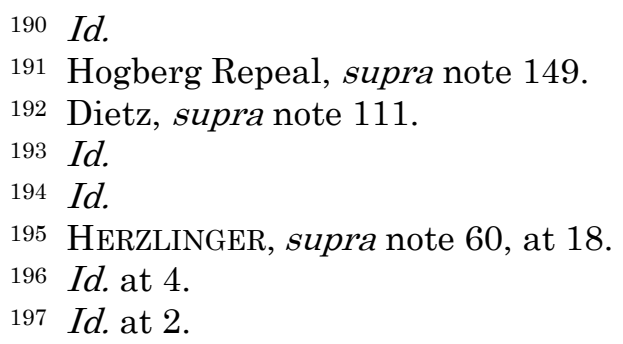


One hospital CEO argued before Congress that a small physician-owned specialty hospital was limiting the ability of his hospital chain to provide free care for the poor and sick by siphoning off his hospitals' most profitable patients. 198 Yet at the same time his hospital chain was allegedly struggling, the hospital chain still earned $\$ 26$ million in profits and held $\$ 50$ million in cash and liquid investments, even after all charitable actions were accounted for. ${ }^{199}$ In fact, very little of the available funds were used to help patients unable to pay their hospital bills, and the hospital actually decreased its charitable care as profits increased. ${ }^{200}$ Community hospitals have used stated philanthropic intentions to persuade the government to enact laws in their favor. Yet, this example of a hospital chain holding onto millions in cash while decreasing charitable care seems to show the hypocrisy of the community hospital arguments.

When Indiana University Health began buying the physician-owners out of its hospitals, the hospital group also announced plans to convert the hospitals to not-forprofits. ${ }^{201}$ Non-profit hospitals do not have to pay income taxes, usually are not required to pay sales and real estate taxes, and are able to borrow using tax-subsidized municipal debt. ${ }^{202}$ U.S. congressional staff members estimated that tax subsidies lowered nonprofit expenses by $\$ 13$ billion in 2002. ${ }^{203}$ By becoming not-for-profits, the local communities will lose the tax income from the facilities to use for fire and police departments, schools, and roads.

Physician-owned hospitals on the other hand, pay income, property, and sales taxes and cannot take advantage of tax-subsidies, thus providing funds to the community for other municipal endeavors. Physicianowned hospitals concede that they provide lower levels of uncompensated care than community hospitals but argue

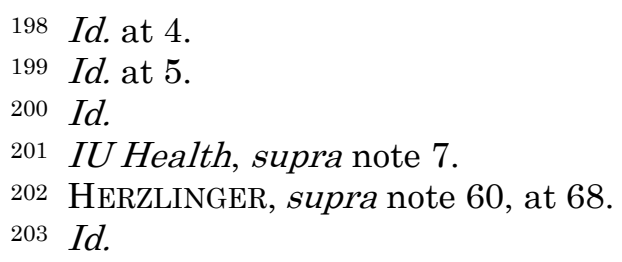


that the taxes that the physician-owned hospitals pay offset the smaller proportion of uncompensated care. ${ }^{204}$ The 2005 HHS report defines "net community benefit" as the sum of uncompensated care costs and tax payments. ${ }^{205}$ In the study, cardiac hospitals had a net community benefit of $3.74 \%$ of total operating revenue ("TOR"), orthopedic \& surgery hospitals had a net community benefit of $7.23 \%$ of TOR, while not-for-profit had a net community benefit of $0.87 \%$ of TOR. ${ }^{206}$ The report even went so far as to include Medicaid shortfalls to adjust the uncompensated care numbers for community hospitals up to $2.27 \%$ of TOR. ${ }^{207}$ The Medicaid shortfall accounts for the fact that Medicaid payments to hospitals were about $4.1 \%$ lower than costs, which is about $1.4 \%$ of total revenue on average nationally. ${ }^{208}$ Even after including the Medicaid shortfall, the physician-owned hospitals still provided a greater net community than community hospitals. 209

\section{Conflict of Interest}

Community hospitals, through groups like the American Hospital Association and the American Federation of Hospitals, lobbied for limits on the expansion of physicianowned hospitals. ${ }^{210}$ In 2006, the American Hospital Association, which represents non-profit hospitals, donated $\$ 1.8$ million to federal candidates. ${ }^{211}$ Community hospitals have argued for years that physician-owners use selfreferral to refer healthier, more profitable patients to physician-owned facilities and leave sicker, costlier patients for community hospitals.

Limiting growth, capping physician ownership, ending some Stark Law exceptions for self-referral bans, and requiring disclosures of physician ownership of facilities and

\footnotetext{
204 Leavitt, supra note 28, at 2-3.

$205 \mathrm{Id}$. at 55.

206 Id. at 58.

207 Id. at 59.

208 Id.

209 Id.

210 Hogberg Repeal, supra note 148.

211 HeRZLINGER, supra note 60, at 64.
} 
potential conflicts of interest when referring patients to those facilities were ideas encouraged by the "Big Hospital" lobby to decrease competition from physician-owned hospitals. ${ }^{212}$ Sandvig believes that critics of physicianowned hospitals are worried that the more efficient way of doing things will push community hospitals toward obscurity. "They see a new model that works very well, that's high-quality, low-cost, better efficiency. It's a case of an innovation that they don't want to have to match," she stated. 213

Community hospitals argue that physician-owned hospitals operate with an inherent conflict of interest, treat the most profitable patients, and place strains on the finances of community hospitals, which in turn reduces key services in those community hospitals. ${ }^{214}$ In the absence of an ownership interest, physicians will consider many different variables in choosing a facility for a patient like the best interests of the patient and convenience. ${ }^{215}$ When hospital ownership interest is added, a physician has the added variable of an economic interest. ${ }^{216}$ This conflict of interest may breach a physician's fiduciary duty to his patient. Community hospitals have a difficult time competing with physician-owned hospitals because federal regulations prohibit the community hospitals from offering anything of value to physicians for referrals. ${ }^{217}$ Community hospitals also still must provide emergency or trauma services and charity care which provide little to no income to the hospital. 218 If this is true, community hospitals are losing out on revenue because physician-owners are referring the profitable patients to physician-owned facilities, and referring the unprofitable or less profitable patients to the community hospitals, to bolster the physician-owned hospital profits and thus the physician-

212 Silva, supra note 43.

213 Id.

214 Id.

215 Lynk \& Longley, supra note 175, at 215

216 Id.

217 Terry, supra note 6.

218 Id. 
owner's income. Eventually community hospitals will be left with little to no funds to provide the emergency and charitable services that Americans have come to expect hospitals to provide.

Along with an ownership interest in any business (including hospitals) comes a share of that business's profits. Critics of physician-owned hospitals claim that physicians have a "financial incentive to refer their least costly and most healthy [] patients to the facility in which they have an ownership interest, while choosing to operate on their sicker and more complex cases in the general hospital, where the costs of lengthy recuperation could be passed on and an emergency room would stand ready in the event of an emergency." 219 Community hospital supporters believe that referring healthier patients to the hospital in which the physician has an ownership interest takes funds away from the community hospital that are normally used to offset the cost of unprofitable procedures and that this action increases health care costs for everyone. ${ }^{220}$

In the traditional physician/hospital relationship, the physician sells his services and the hospital sells its facilities, complementing each other. ${ }^{221}$ However, the relationship is put off balance when the physician has a personal financial interest in a facility that competes with the hospital in which the physician-owner works. ${ }^{222}$ When a physician-owner refers a patient to the hospital he owns he receives financial returns in two ways: once for performing the procedure and once for his portion of the hospital's fee. ${ }^{223}$ This gives physician-owners a greater incentive to refer patients to the facility than non-physicianowners. 224 Patients who may not receive any benefit could be put through expensive, unnecessary procedures if there is a strong financial benefit for the physician-owner. ${ }^{225}$

219 Perry, supra note 13 , at 32.

220 Terry, supra note 6.

221 Lynk \& Longley, supra note 175, at 215

222 Id.

223 Id.

224 Id. at 220 .

225 Id. 
Dr. Arnold S. Relman, professor at Harvard Medical School and editor-in-chief of the New England Journal of Medicine, is quoted in Marc Rodwin's book Medicine, Money and Morals: Physicians' Conflicts of Interest saying "medical care has become a competitive, revenue-seeking industry in which many physicians have an economic interest that goes beyond their personal services. This development undoubtedly affects many of the decisions doctors make, and it certainly adds to the cost of medical care." 226 Rodwin testified about problems created by inappropriate physician self-referrals before the Ways and Means Health Subcommittee in 1993. ${ }^{227}$ Summarized his points were that physician conflicts of interest have existed for over a hundred years; doctors are not subject the same conflict of interest regulations and fiduciary standards as other professions; currently the laws governing physician self-referral are disconnectedly and incompletely pieced together; and the current medical payment system has created the health care spending problem and encouraged corrupt economic incentives for physicians. ${ }^{228}$

However, if physicians were referring patients for unnecessary procedures insurance companies and medical malpractice attorneys would take notice. ${ }^{229}$ Instead, insurance companies are directing patients to physicianowned hospitals, such as Indiana Orthopaedic Hospital, for the physician-owned hospitals' cost efficiencies and medical malpractice attorneys are not filing claims. ${ }^{230}$ Because insurance companies are directing patients toward the less costly, better quality physician-owned hospitals and medical malpractice attorneys are not targeting these physicianowned hospitals, the evidence appears to show that there are no issues concerning physicians recommending unnecessary procedures. Physician Hospitals of America President and senior executive officer of the Kansas City Orthopedic Institute in Leawood, Kansas, a physician-

226 Sutton, supra note 18, at 22.

227 Id.

228 Id.

229 Henry, supra note 9.

230 Id. 
owned facility, Paul Kerens says "Physician owners started getting into the hospital business to provide better patient care and provide efficiencies of care. They are not in it for the money." 231 The average physician invested in a physician-owned hospital owns less than 2 percent of the hospital. 232 The amount of income that would come from each individual patient referred by a physician-owner is so trivial that income generated from a referred patient would not be a major factor in determining where to send a patient for a procedure.

The 2005 HHS report concluded that referral patterns of owner-physicians are consistent with referral patterns of non-owner physicians. ${ }^{233}$ The study found that although physician-owners had high percentages of referrals to the facilities in which the physicians have an ownership interest, the numbers were not surprising because the physician-owners had "an established clinical rapport and favorable working relationship with the facility in which they have an ownership interest." 234 Physicians are more likely to refer their patients to the facility with which the physicians have developed a "primary relationship,"235 which is not necessarily an ownership interest. Also, the report could not find any regular patterns of physicianowners referring patients to their owned-facilities compared to their peers. ${ }^{236}$

The community hospitals may be seen to also have a conflict. In the past, physicians have been self-employed, independent contractors for the hospitals. ${ }^{237}$ Increasingly physicians are becoming salaried employees of community hospitals instead of independent contractors with privileges to practice in the community hospitals. Regina Herzinger points out the fact that by hiring physicians as salaried employees, hospitals are taking advantage of the vertical

231 Id.

232 Perry, supra note 13, at 30.

${ }^{233}$ Leavitt, supra note 28, at 61.

234 Id.

$235 I d$.

236 Id.

237 HerZlinger, supra note 60, at 69. 
integration strategy. 238 This strategy involves owning the sources of your customers and your suppliers. 239 By hiring physicians as hospital employees, community hospitals are ensuring that the physicians will refer patients to the employing hospital. ${ }^{240}$ The hospital will receive the facility fee from the patient's payment and be able to control how much the physician receives as salary from his patient's payments. ${ }^{241}$ An independent physician would refer patients to the hospital that he believes would best serve the patient's needs, ${ }^{242}$ but a physician-employee would be required to refer his patients to the hospital which employs him. In enacting Section 6001 of the ACA, Congress has not "identified any data that suggests that physicians who invest in hospitals have a greater conflict of interest when it comes to referring patients than physicians who are employed by a hospital." 243

\section{CONCLUSION}

Physician-owned hospitals have proven themselves to be a cost efficient way to provide high-quality health care to patients. In an era where health care costs are rising quickly, this proven method of medical care will help keep costs down more so than any alternative. The federal government recently rewarded a significantly high proportion of physician-owned hospitals for the hospital's ability to provide the kind of care that the ACA claims to encourage. The model created by the physicians who started and continue to run physician-owned hospitals is one that can and should be duplicated at all hospitals across the country. These hospitals set the bar high for other hospitals. The Big Hospital lobbying group simply does not want to compete with physician owned hospitals, so community hospital supporters have decided to try to use

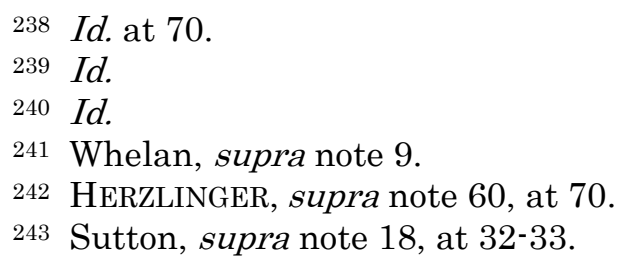


government regulation to eliminate the competition. Any conflicts of interest or overutilization claims by opponents of physician-owned hospitals are offset by the absence of malpractice claims and the continuance of insurance companies to refer patients for treatment at physicianowned facilities. For these reasons, Section 6001 of the ACA should be completely repealed allowing physicians to invest in hospitals and to grow them as the local communities require. 